\title{
Characterizing the thermal ablation of cells for silicon biosensors
}

\author{
Stephane Leahy, Amey Banavali, Wei Kong, Yongjun Lai \\ Department of Mechanical and Materials Engineering, Queen's University, Kingston, Canada.
}

Correspondence: Yongjun Lai. Address: Department of Mechanical and Materials Engineering, Queen's University, Kingston, Canada. Email: lai@queensu.ca

Received: February 8, 2016

Accepted: March 27, 2016

Online Published: April 12, 2016

DOI: $10.5430 /$ jbei.v2n2p109

URL: http://dx.doi.org/10.5430/jbei.v2n2p109

\begin{abstract}
Being able to restore the surface of biosensors to their initial material-free state after immobilization of the biological target can facilitate biosensor development and reduce measurement costs. Thermal ablation has been recently proposed as a new method to conveniently accomplish this using high temperature heating with a hot plate. Key variables related to chip heating are characterized to optimize the effectiveness of thermal ablation. Testing was performed using Poly-LLysine-functionalized silicon-on-insulator chips and E. coli. An analysis based on image processing demonstrates that the maximum temperature reached by the chip and the length of time the chip is held at the maximum temperature significantly affect cell removal, while the heat rate at which the chip goes from room temperature to the maximum temperature does not affect cell removal. It was found that nearly all cells can be removed by heating the chip at $425^{\circ} \mathrm{C}$ for $10 \mathrm{~s}$ or by heating the chip at $375^{\circ} \mathrm{C}$ for $100 \mathrm{~s}$.
\end{abstract}

\section{Key words}

Biosensors, Regeneration, Thermal ablation, Heating, Hot plate, Poly-L-Lysine, E. coli, Image processing

\section{Introduction}

Many biosensors rely on the interaction between a biological target and a bioreceptor immobilized to a sensing surface in order to generate a quantifiable signal ${ }^{[1,2]}$. Examples of such biosensors include static and dynamic cantilever biosensors ${ }^{[3,4]}$, amperometric and piezoresistive biosensors ${ }^{[5]}$, and micro-Raman spectroscopy biosensors ${ }^{[6]}$. After one or many measurements, most of the bioreceptor sites become occupied by the biological target and the sensing surface becomes covered by the biological target or contaminants. When this occurs, fewer new biological targets may bind to the sensing surface and the biosensor becomes less effective ${ }^{[7]}$. To perform new measurements, a new biosensor with a clean sensing surface and a new layer of bioreceptors must be used, or the used biosensor must be regenerated in order to restore the sensing surface and the bioreceptors to their original state. Being able to conveniently regenerate the biosensor is valuable because it can facilitate the development of biosensors and reduce the cost of each measurement in end-user applications ${ }^{[5]}$.

Several methods exist to regenerate biosensors by overcoming the attractive forces between the bioreceptor and the analyte, as shown in a recent review by Goode et al. ${ }^{[1]}$. The most popular method is chemical regeneration, where the 
solvent environment is altered chemically. This is achieved by applying high- or low-pH buffers to the biosensor to denature the bioreceptor and change the ionic strength of the environment ${ }^{[8,9]}$, by using detergents to encourage solubility, or by using glycine to encourage separation. Another method is thermal regeneration, where the temperature is sufficiently elevated in order to increase the kinetic energy of molecules and overcome binding forces without denaturing the bioreceptor ${ }^{[1]}$. Both of these methods are useful because their leave the bioreceptor intact. However, they can require specific chemicals and delicate and complex procedures. Other methods that do not necessarily leave the biosensor intact are ultrasonic cleaning and mechanical cleaning. These methods are limited because they may not effectively remove the biological target and they can damage the microstructure of biosensors.

In previous work by our group, a new method using thermal ablation was presented to regenerate a silicon cantilever biosensor ${ }^{[10]}$. The motivation behind this method was that silicon biosensors could be conveniently regenerated by heating them to a high temperature, because silicon, silicon derivatives, and other heavy metals are much more resistant to high temperatures than biological material. Previous results showed that thermal ablation at $370^{\circ} \mathrm{C}$ for 10 min with a hot plate removes $82 \%$ of bound $E$. coli cells based on the resonant frequency shifts of a cantilever biosensor ${ }^{[10]}$. The high temperature heating did not affect the frequency response of the cantilever over hundreds of tests, indicating that the chip, including the Aluminum Nitride piezoelectric film, was not damaged. The results also suggested that cell removal can be improved by heating the chip at a higher temperature, heating it for a longer time, and heating it up faster.

The purpose of this study is to characterize how the variables related to chip heating affect the effectiveness of thermal ablation. A better understanding of the effect of these variables is valuable for optimizing thermal ablation to maximize cell removal and minimize heating time and temperature. In this study, the effectiveness of thermal ablation is quantified by using image processing instead of measuring the resonant frequency shifts of a cantilever. This approach is more general and is applicable to all surfaces to which cells are attached, including biosensors, surgical devices, and other medical equipment.

Figure 1. Image of the experimental setup

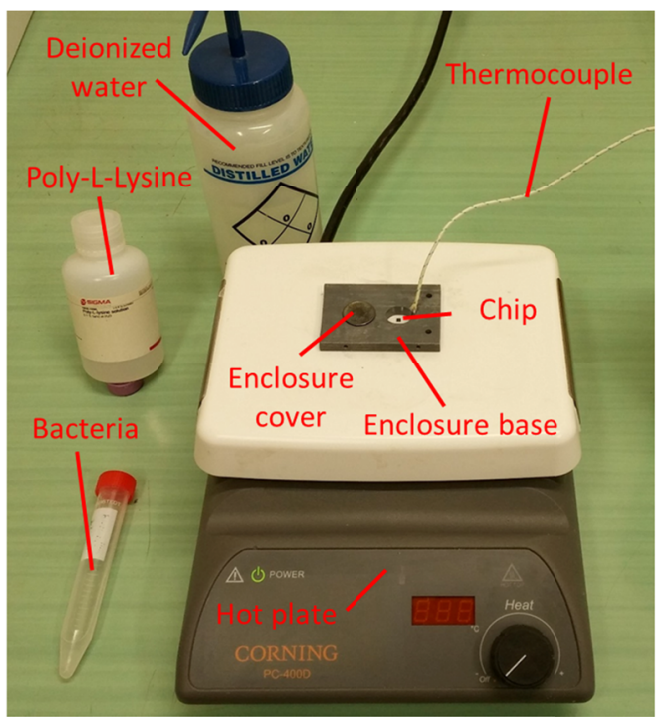

\section{Materials and methods}

\subsection{Experimental setup}

Thermal ablation tests were conducted using $1 \mathrm{~mm} \times 1 \mathrm{~mm}$ silicon-on-insulator chips micro-machined with SOIMUMPs ${ }^{[11]}$, a Corning PC-400D hot plate, E. coli bacteria, deionized water, and Poly-L-Lysine (see Figure 1). 
Thermocouple measurements showed that the chip surface reaches a maximum temperature of $370^{\circ} \mathrm{C}$ when it is placed at the center of the hot plate and the hot plate is set to its highest temperature. Since thermal ablation may be more effective at higher temperatures ${ }^{[10]}$, the maximum temperature of the chip surface was increased by placing the chip inside an thermally insulated enclosure on top of the hot plate (see Figure 1). The base of the enclosure consists of a 25-mm-thick aluminum base and the cover consists of a 25 -cent piece.

Figure 2. Temperature profile of the hot plate surface and the chip surface when an enclosure is used

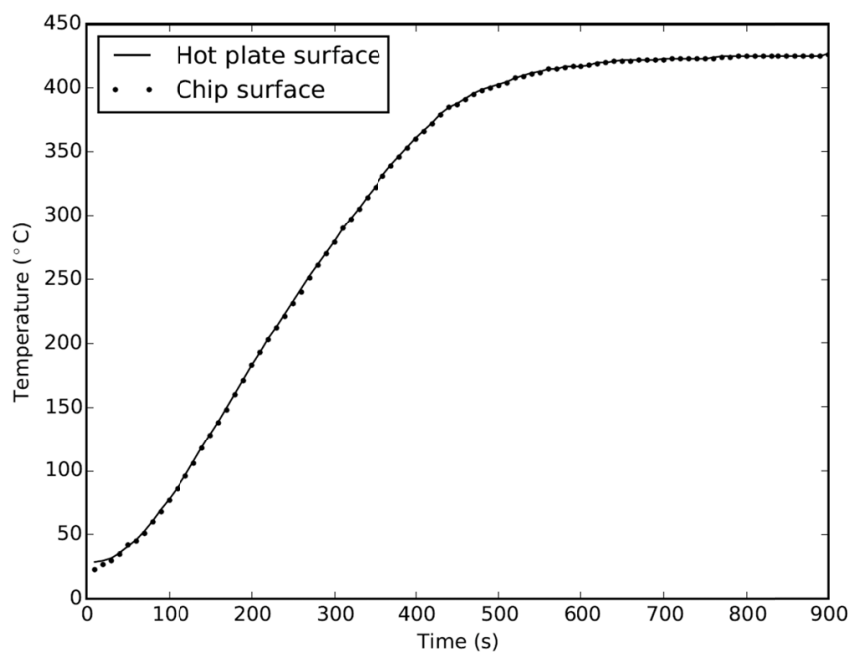

The temperature profile of the hot plate surface and the chip surface when an enclosure is used is shown in Figure 2. Using the enclosure, the chip reaches a steady state temperature of $425^{\circ} \mathrm{C}$ after about $600 \mathrm{~s}$. The steady state temperature is $55^{\circ} \mathrm{C}$ higher than the temperature reached without using the enclosure. Based on preliminary results concerning cell removal, this steady state temperature was deemed high enough for the study. Moreover, as shown in the figure, the temperature profile of both the hot plate surface and the chip surface are nearly the same, indicating that the chip heats very fast. The chip has a high thermal conductivity [149 W/ $(\mathrm{m} \cdot \mathrm{K})]$, it has an area of $1 \mathrm{~mm}^{2}$, and a thin thickness of $400 \mu \mathrm{m}^{[12]}$. Thus it is expected to respond to temperature changes quickly. Based on these results, it was assumed that the chip reaches the temperature of the hot plate instantaneously in the temperature range of interest.

Table 1. Testing scheme

\begin{tabular}{llll}
\hline Variable & Maximum temperature $\left({ }^{\circ} \mathbf{C}\right)$ & Time at maximum temperature $(\mathbf{s})$ & Heat rate \\
\hline \multirow{4}{*}{ Maximum temperature } & 275 & & \\
& 325 & 10 & Step \\
& 375 & & \\
& 425 & 10 & \\
Time at maximum temperature & 275 & 100 & Step \\
& 325 & 1,000 & \\
& & 10 & Step \\
& 275 & 100 & Ramp \\
Heat rate & 1,000 & Step \\
& 425 & 0 & Ramp \\
\hline
\end{tabular}

\subsection{Testing scheme}

Three variables that affect the effectiveness of thermal ablation were studied: 1) the maximum temperature reached by the chip; 2) the length of time the chip is maintained at the maximum temperature; 3) the heat rate for the chip to heat from 
room temperature to the maximum temperature. A testing scheme (see Table 1) was prepared to determine the effect of each variable. In the testing scheme, the value of one variable was changed while the value of the two other variables was held constant. The maximum temperature ranged from $275^{\circ} \mathrm{C}$ to $425^{\circ} \mathrm{C}$, the time at maximum temperature ranged from 0 to $1,000 \mathrm{~s}$, and the heat rate was either a step increase or a ramp increase. This testing scheme provides results for a practical range of values.

For the heat rate with a step increase, the chip was placed on the hot plate when the chip was at room temperature and the hot plate had settled at the maximum temperature, giving a very high heat rate (nearly instantaneous). For the heat rate with a ramp increase, the chip was placed on the hot plate when both the chip and the hot plate were at room temperature, and then the hot plate was set to the desired temperature. For a maximum temperature of $425^{\circ} \mathrm{C}$, the ramp heat rate is roughly $1.2^{\circ} \mathrm{C} / \mathrm{s}$ (see Figure 2), and for a maximum temperature of $275^{\circ} \mathrm{C}$, the ramp heat rate is slightly lower.

\subsection{Testing procedure}

Three previously used chips were taken for testing. Before running any tests, the chips were restored to a reference condition by heating them on the hot plate at $425^{\circ} \mathrm{C}$ for $15 \mathrm{~min}$ and letting them cool to room temperature. This seemed to remove all cells from the chip.

In a typical test, the chip was first functionalized by letting a $100 \mu \mathrm{l}$ droplet of Poly-L-Lysine solution $\left(0.1 \% \mathrm{w} / \mathrm{v} \mathrm{H}_{2} \mathrm{O}\right)$ from Sigma-Aldrich sit on its surface for $5 \mathrm{~min}$. The chip was lifted with tweezers and was rinsed with deionized water for $20 \mathrm{~s}$ and allowed to dry in air at room temperature. During rinsing, the chip was tilted and the water flowed from the top of the chip to the bottom of it to minimize the attachment of contaminants. The first image of the chip was recorded. A Motic PSM-1000 microscope at $10 \times$ magnification with a SONY XCD-V60CR camera with $640 \times 480$ pixels was used to record the image. Then a $100 \mu \mathrm{l}$ droplet of an $E$. coli $\mathrm{K}-12$ sample with a concentration of $2.33 \times 108 \mathrm{cells} / \mathrm{ml}$ was placed on its surface using a $10 \mu \mathrm{l}$ pipette and the droplet remained there for $5 \mathrm{~min}$. This size of droplet ensured that the entire surface of the chip was in contact with the sample, and the concentration was high enough to allow significant cell immobilization in a short period. The chip was again rinsed in the same manner previously described and allowed to dry. The second image of the chip was recorded. Then the chip was heated on the hot plate according to the testing scheme (see Table 1) and allowed to cool to room temperature. The third image of the chip was recorded. This procedure provided three images of the chip: one image when it was clean (see Figure 3A), one image after cells where immobilized (see Figure 3B), and one image after thermal ablation (see Figure 3C). These images are referred to as raw images. A total of 35 experiments were conducted following this procedure.

\subsection{Image processing}

The raw images were processed to quantify the effectiveness of thermal ablation. As an example, Figure 3 shows the raw and processed images for one test where the maximum temperature was $425^{\circ} \mathrm{C}$, the time at maximum temperature was $10 \mathrm{~s}$, and the heat rate was a step increase.

In the top row of the figure, the raw images are shown. In Image A, the surface of the chip is clean. A contaminant, possibly a dust particle, is identified with a red square. A gold landing pad is also observed in the left side of the image. In Image $B$, the chip is speckled with immobilized cells, which appear as small dark dots. One particularly large cell $(\approx 5 \mu \mathrm{m}$ long) is identified with a red circle. Most of the other cells seem to be about 1-3 $\mu \mathrm{m}$ long, which agrees with the length of E. coli reported in the literature. The contaminant is again identified with the red square. In Image $\mathrm{C}$, the surface of the chip is clean again, and no cells are observed. The contaminant is still observed and is again identified. The contaminant seems to be resistant to high temperature heating and rinsing. Another contaminant, possibly a large dust particle, is also identified with a red triangle.

In the bottom row of the figure, the processed images are shown. The processed images were obtained with GIMP and MATLAB using the following image processing procedure. First, the raw images were aligned using an image registration 
plugin for GIMP and then they were converted from RBG to grayscale. Then two new images were produced by performing the subtractions (see Figure 3, B-A) and (see Figure 3, C-B). These subtractions were used instead of the subtraction (see Figure 3, C-A) because they provide a measure of the effectiveness of thermal ablation that is independent of the number of added cells, while (see Figure 3, C-A) does not. The new images were converted to black and white using a threshold of 0.12 , and they were cropped to remove inconsistent areas such as the gold pad. During processing, the brightness did not need to be adjusted because all images had the same brightness. No moving average filter was required either, because the images had very little Gaussian or impulsive noises. From this procedure, two black and white images were produced. One image shows the cells that were added (see Figure 3, B-A), and the other image shows the cells that were removed (see Figure 3, C-B). Encircled in both images is the same large cell that was encircled in Image B, indicating that this cell was first added to the chip, and then it was removed. The contaminant identified with the red square in Images A, B and C does not appear in Image B-A or Image C-B because it does not change states. The contaminant identified with a red triangle in Image $\mathrm{C}$ does not appear in Image C-B because it was located in a section of the image that was cropped out during processing.

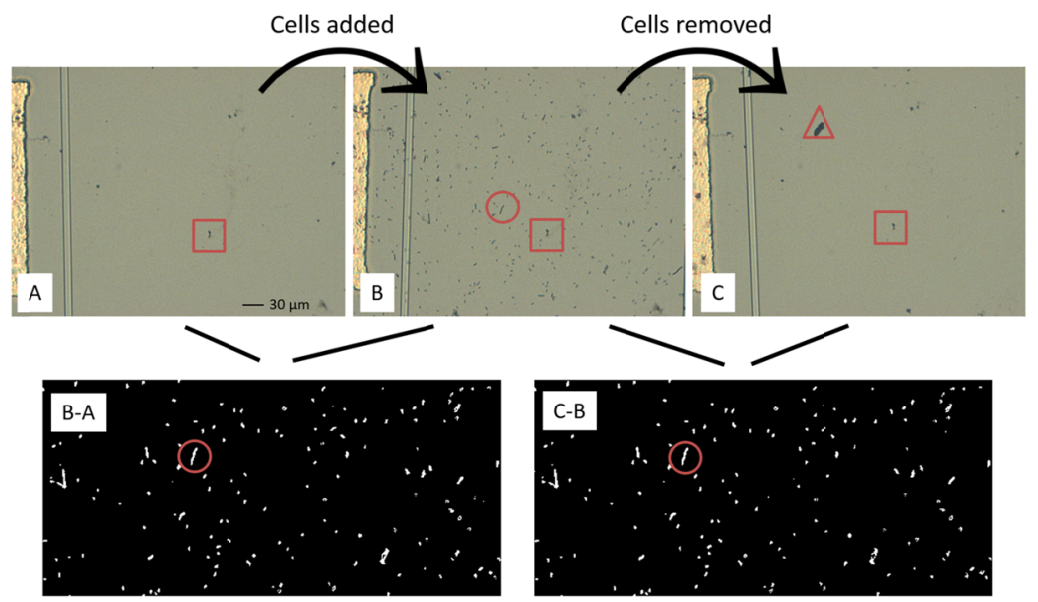

Figure 3. Raw image taken before cell immobilization (A), after cell immobilization (B), and after thermal ablation (C). Processed image showing the pixels that changed when cells were added (B-A) and when cells were removed (C-B). Key areas are enclosed in red.

\subsection{Cell removal calculation}

The percentage of white pixels was calculated for each of the processed images. The variable $\mathrm{w}_{(\mathrm{B}-\mathrm{A})}$ is the percentage of white pixels in Figure 3 (B-A), and it represents the percentage of the chip area where cells were added. The variable $\mathrm{w}_{(\mathrm{C}-\mathrm{B})}$ is the percentage of white pixels in Figure 3 (C-B), and it represents the percentage of the chip area where cells were removed. Finally, the ratio $\mathrm{w}_{(\mathrm{C}-\mathrm{B})} / \mathrm{w}_{(\mathrm{B}-\mathrm{A})}$ was calculated. This ratio represents the percentage of cells that were removed relative to the percentage of cells that were added. This ratio was used to quantify the effectiveness of thermal ablation, and it is from here on referred to as cell removal. In Figure 3, the percentage of cells added is $\mathrm{w}_{(\mathrm{B}-\mathrm{A})}=1.437 \%$, the percentage of cells removed is $\mathrm{w}_{(\mathrm{C}-\mathrm{B})}=1.430 \%$, and the cell removal percentage is $\mathrm{w}_{(\mathrm{C}-\mathrm{B})} / \mathrm{w}_{(\mathrm{B}-\mathrm{A})}=99.5 \%$.

\section{Results and discussions}

\subsection{Raw images}

Select raw images of the chips after thermal ablation under different heating conditions are shown in Figure 4. Each image is equivalent to Image $\mathrm{C}$ in Figure 3 for one test. It should be noted that in the images here, as in Image $\mathrm{C}$ in Figure 3, various large spots appear. These spots are clearly too large to be $E$. coli cells and they are therefore considered to be 
contaminants. These contaminants were not removed after thermal ablation. However, in this study, we are interested in the removal of cells, and these images provide a good understanding of how the heating parameters affect cell removal.
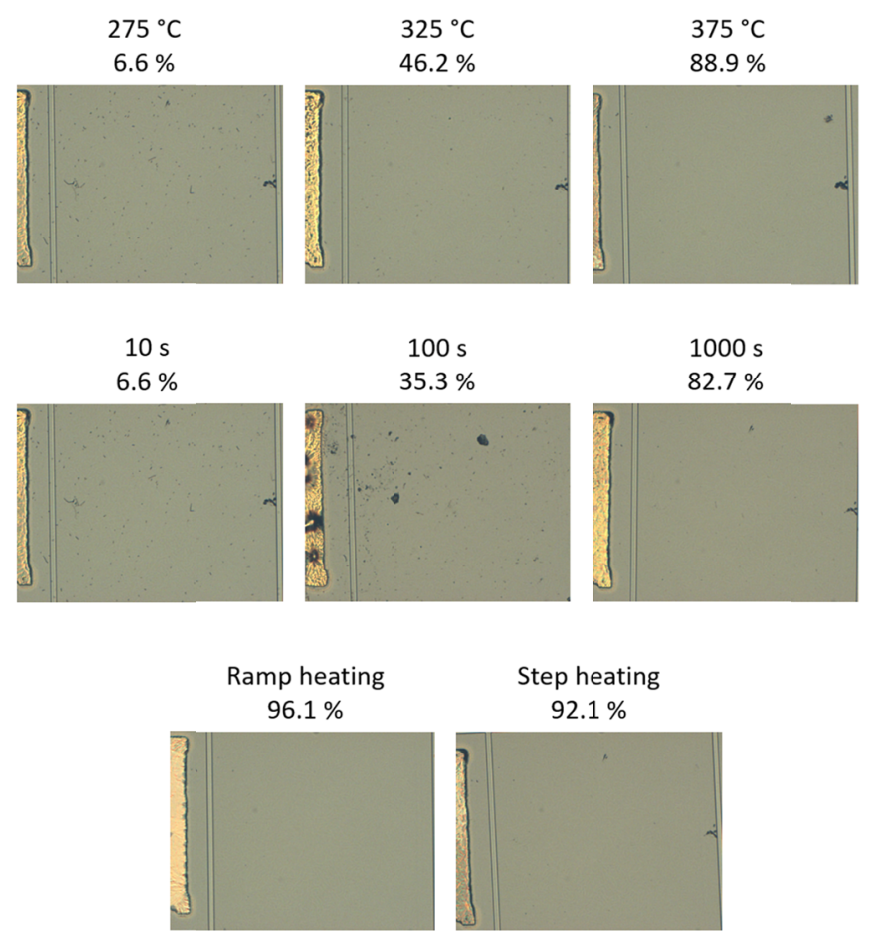

Figure 4. Raw images after thermal ablation under different heating conditions and corresponding cell removal percentage obtained from image processing

In the top row, the maximum temperature varies, while the time at maximum temperature is $10 \mathrm{~s}$ and the heat rate is a step increase. With a maximum temperature of $275^{\circ} \mathrm{C}$, few cells are removed from the chip (6.6\%), and the remaining cells appear as dark spots. With a maximum temperature of $325^{\circ} \mathrm{C}$, nearly half the cells are removed, and the remaining cells appear as faint spots. The remaining cells appear fainter because part of their cellular content has been removed. With a maximum temperature of $375^{\circ} \mathrm{C}$, nearly all the cells seemed to be removed. These images show that an increase in maximum temperature between the range of $275^{\circ} \mathrm{C}-375^{\circ} \mathrm{C}$ leads to an increase in cell removal when the time at maximum temperature is $10 \mathrm{~s}$ and the heat rate is a step increase.

In the middle row, the time at maximum temperature varies, while the maximum temperature is $275^{\circ} \mathrm{C}$ and the heat rate is a step increase. With a time of $10 \mathrm{~s}$, few cells are removed from the chip, and the cells appear as dark spots. With a time of $100 \mathrm{~s}$, more cells are removed, but many still remain on the chip, and they appear as dark spots. With a time of 1,000 s, most of the cells are removed, and the few remaining cells appear as faint spots. These images show that an increase in time at the maximum temperature between the range of $10 \mathrm{~s}-100 \mathrm{~s}$ leads to an increase in cell removal when the temperature is $275^{\circ} \mathrm{C}$ and the heat rate is a step increase.

In the bottom row, one image is shown for ramp heating and another is shown for step heating, for a maximum temperature of $425^{\circ} \mathrm{C}$ and a time at maximum temperature of $10 \mathrm{~s}$. In both images, no cells are observed. This suggests that that the heat rate does not have an important effect on cell removal when the maximum temperature is $425^{\circ} \mathrm{C}$. When the maximum temperature is lower, perhaps the heat rate has more of an effect.

\subsection{Analysis of processed images}

Observations made from the raw images led to the following conclusions: cell removal increases with the maximum temperature and with the time at maximum temperature, but cell removal does not change significantly with the heat rate. 
To further validate these conclusions, the processed images for all the tests based on the testing scheme (see Table 1) were analyzed. The relationship between the cell removal percentage and each of the three variables of interest was obtained.

Figure 5. Relationship between cell removal and the maximum temperature when the time at maximum temperature is $10 \mathrm{~s}$ and the heat rate is a step increase

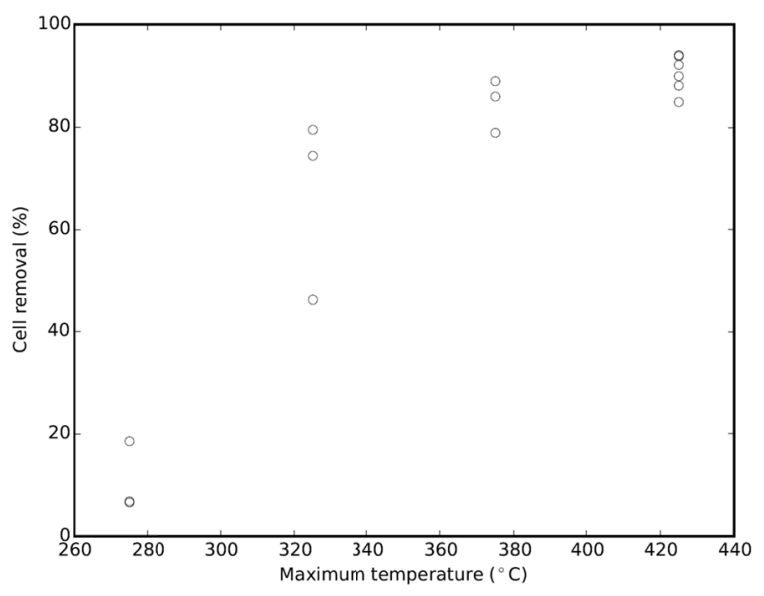

Figure 5 shows that cell removal increases with the maximum temperature for a given time at maximum temperature of $10 \mathrm{~s}$. The cell removal percentage is below $20 \%$ at $275^{\circ} \mathrm{C}$. Above this temperature, it seems to increase non-linearly, and then it saturates at $425^{\circ} \mathrm{C}$. At each temperature, the cell removal percentage varies by approximately $10 \%$. These variations are attributable to slight differences in rotational and translational alignment in the images during processing and the attachment or removal of contaminants during testing. Considering this variations, it can be concluded that nearly all the cells are removed at $425^{\circ} \mathrm{C}$. At $320^{\circ} \mathrm{C}$, there is one data point that is significantly lower than the others. This can be explained by the fact that the images used to obtain this data point had larger alignment errors.

Figure 6. Relationship between cell removal and the time at maximum temperature when the heat rate is a step increase. No data points were obtained at $1,000 \mathrm{~s}$ for $375^{\circ} \mathrm{C}$, because it was clear that the cell removal percentage saturates.

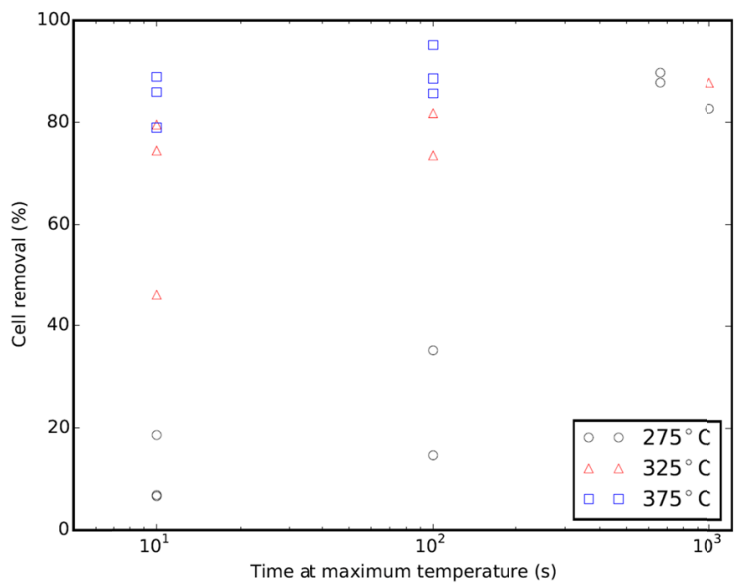

Figure 6 shows that cell removal increases with the time at maximum temperature, and that this effect is more significant at lower temperatures than at higher temperatures. At $275^{\circ} \mathrm{C}$, the cell removal percentage is below $20 \%$ when the time at maximum temperature is $10 \mathrm{~s}$, but the cell removal percentage increases to about $90 \%$ when the time at maximum temperature is $1,000 \mathrm{~s}$. At $325^{\circ} \mathrm{C}$, a similar yet more gradual increase in cell removal percentage is observed, with seemingly no increase in cell removal at $1,000 \mathrm{~s}$. At $375^{\circ} \mathrm{C}$, the trend is still slightly apparent. However, at this temperature the time at maximum temperature seems to have little effect on cell removal since most of the cells are already removed at $10 \mathrm{~s}$. The linear trends in the semi-log graph suggest an exponential relationship between cell removal and the time at maximum temperature. It can be concluded that nearly all the cells are removed at $375^{\circ} \mathrm{C}$ when the time at maximum temperature is above $100 \mathrm{~s}$. 
Quantifying the relationship between cell removal and the heat rate is more challenging, because the heat rate and the time at maximum temperature are related. As shown in Figure 6, cell removal increases significantly, even at lower temperatures, when the time at maximum temperature is increased. Therefore, with a lower heat rate, cell removal is expected to increase, regardless of the effect of heat rate, since the time near the maximum temperature increases. This highlights the importance of dissociating the effect of the time at maximum temperature from the effect of the heat rate in this analysis.

Table 2. Relationship between cell removal and heat rate under different conditions. The cell removal percentage represents the average value for three tests with a $95 \%$ confidence interval

\begin{tabular}{llll}
\hline Heat rate & Maximum temperature $\left({ }^{\circ} \mathbf{C}\right)$ & Time at maximum temperature (s) & Cell removal $(\%)$ \\
\hline Ramp $\left(<1.2^{\circ} \mathrm{C} / \mathrm{s}\right)$ & 275 & 0 & $20.1 \pm 11.9$ \\
Step & 275 & 660 & $88.8 \pm 1.9$ \\
Ramp $\left(1.2^{\circ} \mathrm{C} / \mathrm{s}\right)$ & 275 & 10 & $10.7 \pm 7.7$ \\
Step & 425 & 300 & $96.8 \pm 2.8$ \\
\hline
\end{tabular}

Table 2 shows the average cell removal percentages for different heat rate tests. These tests are similar to those planned in the testing scheme in Table 2, and they provide useful data for analyzing the effect of the heat rate. At $275^{\circ} \mathrm{C}$, the cell removal percentage is low for ramp heating when the time at maximum temperature is $0 \mathrm{~s}$. When step heating is used and the time at maximum temperature is nearly the same $(10 \mathrm{~s})$, the cell removal percentage is still low and within the same range considering the confidence intervals. This suggests that the heat rate has little effect on cell removal, since extreme changes in heat rate led to insignificant changes in cell removal percentages. However, when ramp heating is used, and the time at maximum temperature is extended to $660 \mathrm{~s}$, the cell removal increases significantly. This suggests that the time at maximum temperature has a much more important effect than heat rate. Finally, when comparing ramp heating and step heating at $425^{\circ} \mathrm{C}$ for similar times at maximum temperature (within $200 \mathrm{~s}$ ), insignificant changes in cell removal are observed.

The results found in this study are in good agreement in general with the results found in a previous publication ${ }^{[10]}$, where the resonant frequency shifts of a cantilever biosensor were measured after thermal ablation. The resonant frequency shifts showed that heating the biosensor at $370^{\circ} \mathrm{C}$ with ramp heating in 10 min intervals led to insignificant increases in cell removal. Similarly, here it was demonstrated that the heating time has little influence on cell removal at a temperature of $375^{\circ} \mathrm{C}$. The resonant frequency shifts also suggested that increasing the temperature beyond $370^{\circ} \mathrm{C}$ increases cell removal, and here is was shown that increasing the temperature to $425^{\circ} \mathrm{C}$ does indeed increase cell removal. Finally, the resonant frequency shifts (three trials) suggested that at $370^{\circ} \mathrm{C}$ step heating provides higher cell removal than ramp heating. Here it was demonstrated that this is not the case. Many trials using image processing showed that the heat rate does not significantly affect cell removal. Ultimately, the analysis using resonant frequency shifts provided useful trends in cell removal, but the analysis here using image processing provided a much more in-depth picture of thermal ablation.

\section{Conclusions}

In this study, three key variables that determine the effectiveness of the thermal ablation of biosensors were characterized using image processing. Image processing is a simple method to rapidly and accurately quantify cell removal. Results disclosed that the maximum temperature reached by the chip and the length of time the chip is maintained at the maximum temperature significantly affect the cell removal percentage. The results also revealed that the rate at which the chip is heated from room temperature to the maximum temperature (either a step or a ramp increase) has an insignificant effect on the cell removal percentage. It was found that nearly all cells can be removed by heating the chip at $425^{\circ} \mathrm{C}$ for $10 \mathrm{~s}$ or by heating the chip at $375^{\circ} \mathrm{C}$ for $100 \mathrm{~s}$. The results are applicable for a range of chip material and biological material and can be used to optimize the thermal ablation of biosensing surfaces based on the application. Future work involves the 
integration of a thermal ablation system onto a biosensor, thus removing the need to use a hot plate. Future work could also investigate whether this regeneration method is effective when the chip is covered by antibodies or non-biological chemicals.

\section{Acknowledgement}

The authors would like to thank NSERC for funding support and CMC Microsystems for fabrication service support.

\section{References}

[1] Goode JA, Rushworth JVH, Millner PA. Biosensor Regeneration : A Review of Common Techniques and Outcomes. Langmuir. 2015. PMid:25402969. http://dx.doi.org/10.1021/la503533g

[2] Ziegler C. Cantilever-based biosensors. Anal. Bioanal. Chem. 2004 Aug; 379(7-8): 946-59. PMid:15338089. http://dx.doi.org/10.1007/s00216-004-2694-y

[3] Lavrik NV, Sepaniak MJ, Datskos PG. Cantilever transducers as a platform for chemical and biological sensors. Rev. Sci. Instrum. 2004; 75(7): 2229. http://dx.doi.org/10.1063/1.1763252

[4] Raiteri R, Grattarola M, Butt HJ, et al. Micromechanical cantilever-based biosensors. Sensors Actuators B Chem. 2001; 79: 11526. http://dx.doi.org/10.1016/S0925-4005(01)00856-5

[5] Lalauze R. Chemical Sensors and Biosensors. London: ISTE Ltd. 2012. http://dx.doi.org/10.1002/9781118561799

[6] Liao DS, Raveendran J, Golchi S, et al. Fast and sensitive detection of bacteria from a water droplet by means of electric field effects and micro-Raman spectroscopy. Sens. Bio-Sensing Res. 2015.

[7] Leahy S, Lai Y. An hourglass design with electrokinetic sampling and electrothermal actuation for micro biosensors. Sensors Actuators B Chem. 2016; 223: 123-30. http://dx.doi.org/10.1016/j.snb.2015.09.045

[8] Mutharasan R. Principles of Bacterial Detection : Biosensors, Recognition Receptors and Microsystems. New York: Springer. 2008.

[9] Campbell GA, Mutharasan R. Near real-time detection of Cryptosporidium parvum oocyst by IgM-functionalized piezoelectricexcited millimeter-sized cantilever biosensor. Biosens. Bioelectron. 2008; 23(7): 1039-45. PMid:18054480. http://dx.doi.org/10.1016/j.bios.2007.10.017

[10] Leahy S, Lai Y. Regenerating silicon biosensors through thermal ablation with a hot plate. Sens. Bio-Sensing Res. $2015 ; 6$ : 25-7. http://dx.doi.org/10.1016/j.sbsr.2015.10.002

[11] Cowen A, Hames G, Monk D, et al. SOIMUMPs Design Handbook. 2011.

[12] Cowen A, Hames G, Glukh K, et al. PiezoMUMPs Design Handbook. 2013. 